\title{
A comparative evaluation of three common airway humidification methods for patients with severe traumatic brain injury
}

\author{
Xiaohong Yin ${ }^{1,2,3 \#}$, Lei Yang ${ }^{1,2,3}$, Hua Sun ${ }^{1,2,3}$, Zhilei Yun $^{1,2,3}$, Yuxia Wang ${ }^{1,2,3}$, Banyou Ma ${ }^{1,2,3}$ \\ ${ }^{1}$ The Department of Neurosurgery, Center for Critical Medicine, The Forth People's Hospital of Changzhou, Changzhou, China; ${ }^{2}$ The Department \\ of Neurosurgery, Center for Critical Medicine, Changzhou Tumor Hospital, Changzhou, China; ${ }^{3}$ The Department of Neurosurgery, Center for \\ Critical Medicine, Changzhou Tumor Hospital Affiliated to Soochow University, Changzhou, China \\ Contributions: (I) Conception and design: X Yin, B Ma; (II) Administrative support: B Ma; (III) Provision of study materials or patients: X Yin, L Yang; \\ (IV) Collection and assembly of data: B Ma, L Yang, H Sun; (V) Data analysis and interpretation: Z Yun; (VI) Manuscript writing: All authors; (VII) \\ Final approval of manuscript: All authors. \\ \#These authors contributed equally to this work. \\ Correspondence to: Banyou Ma. Center for Neurosurgery, The Fourth People's Hospital of Changzhou, 68 Honghe Road, Changzhou 213022 , China. \\ Email: 172422603@qq.com.
}

\begin{abstract}
Background: Airway humidification methods are commonly used in clinical practice, but no clear consensus exists on which particular method is best suited for specific clinical conditions.

Methods: In this retrospective study, we carried out a quantitative evaluation of three methods commonly used for patients with severe traumatic brain injury (STBI). We recruited 150 patients who received airway humidification after tracheotomy. Subjects were divided into three groups according to the humidification method they received which included oxygen atomizer (OA) group, heat and moisture exchangers (HMEs) group, and heated humidifiers (HHs) group. Variables including phlegm viscosity, humidification effects, phlegm formation rates, daily sputum inhalation times, airway spasm, secondary lung infections, daily nursing load, and evaluation of nurse job satisfaction levels were documented.

Results: Results indicated that the OA tended to cause either insufficient or excessive humidification, whereas phlegm scab formation was significantly reduced in HHs. HMEs and HHs displayed equal humidification effects, and a similar daily sputum induction and consequent nursing load. Airway spasm was a frequent occurrence in OA. The severity, but not the infection ratio, of secondary infection decreased significantly in HHs by the $30^{\text {th }}$ day. The OA significantly reduced nursing load, but demonstrated the worst humidification effects.
\end{abstract}

Conclusions: Overall results suggested that the HHs is more suitable for airway nursing of STBI patients who are bedridden for extended periods.

Keywords: Airway humidification methods; severe traumatic brain injury (STBI); respiratory care

Submitted Sep 29, 2020. Accepted for publication Nov 19, 2020.

doi: 10.21037/apm-20-2135

View this article at: http://dx.doi.org/10.21037/apm-20-2135

\section{Introduction}

Severe traumatic brain injury is often accompanied by respiratory difficulties such as hypoxic asphyxia and elevated intracranial pressure, which in turn can contribute to further deterioration in the patient's clinical status. Tracheotomy establishes an artificial airway that maintains respiratory tract patency, and it is a key procedure in the early treatment of severe traumatic brain injury (1). During normal breathing, the upper respiratory tract will warm and moisturize the inhaled gas. However, when an artificial airway is established, this natural warming and humidification effect is lost and leads to dry oxygen intake 
that can damage the trachea and bronchial mucosa (2), and reduce the movement of the respiratory cilia. This in turn may cause additional complications such as respiratory tract blockage, pulmonary dilatation, pneumonia, posterior pituitary dysfunction, and additional cognitive dysfunction (3-5). Therefore, oxygen must be humidified prior to inhalation. One previous study demonstrated that heated humidification improved clinical outcomes in children with tracheostomies (6), and other studies have suggested that humidification is essential for airway protection in both invasive and noninvasive mechanical ventilation (7).

There are several different types of airway humidification procedures applied in clinical practice. Oxygen atomizer (OA), heat and moisture exchangers (HMEs) and heated humidifiers (HHs) humidification methods were among the most commonly used methods, and OA is a typical method among which. OA atomized the liquid via a high-speed of oxygen flow, and the humidification fluid transform into aerosol and helps to humidify the airway (8). Each method has its disadvantages (9-11), and comparative studies have been conducted to determine which is the optimum method for particular clinical presentations. For instance, study indicated that $\mathrm{OA}$ would not induce hypoxia when the nurse carried out sputum suction, and the patients presented good tolerance (12). Study comparing HMEs with HHs in adults and children who needed mechanical ventilation found no differences in the two methods, although the authors recommended further comparison of HMEs to HHs in pediatric and neonatal patients (13). Although comparative studies abound in the literature, evidence for the method of choice in severe traumatic brain injury (STBI) patients is lacking, and doctors often choose the method they are most familiar with. Therefore, it is important to perform a systematic evaluation of the most suitable method of airway humidification for STBI patients. A previous study had carried out a comparative evaluation among three humidification methods in STBI patients (14), while the three methods we evaluated here were absolutely different from those in previous study, and the evaluation indexes were more comprehensive. Indeed, advantages and disadvantages of the standard airway humidification methods have also been observed in the neurosurgical care of patients with STBI at our hospital, and yet no agreement concerning the use of these methods has been reached. In this study, we chose the three most-respected and commonly used methods in the world for comparison. Our aim was to identify the optimal method of airway humidification for STBI patients, and to further inform the choice airway of humidification methods in clinical practice.

We present the following article in accordance with the STROBE reporting checklist (available at http://dx.doi. org/10.21037/apm-20-2135).

\section{Methods}

\section{Study design and subjects}

This project was approved by the Ethics Committee of the Changzhou Tumor Hospital (2019-SY-014) and all patients gave consent to participate in the study. All procedures performed in this study involving human participants were in accordance with the Declaration of Helsinki (as revised in 2013). A total of 150 patients with STBI who required tracheotomy, and who were admitted to the neurosurgery department of our hospital between January 2016 and December 2018 were included in the cross-section study. All patients met the inclusion criteria conditions, and informed consent to participate was given by all patients or their guardians. Patients were divided into three groups according to the humidification method they received during the in-hospital duration, and the data were analyzed after collected from the daily nursing records. After excluded the patients that not meet the inclusion standards, the patients were divided into the following groups: OA $(\mathrm{n}=50)$, HMEs $(\mathrm{n}=50)$, and HHs $(\mathrm{n}=50)$. Inclusion criteria were as follows: diagnosis of traumatic brain injury or cerebral hemorrhage, Glasgow Coma Scale (GCS) score $\leq 8$ points, no underlying lung disease, no mechanical ventilation. Patients were excluded for the following reasons: blood loss of $>5 \mathrm{~mL}$ on the day following tracheotomy, mechanical ventilation required 3 days after tracheotomy, in patient hospitalization $<3$ days, death or automatic discharge, the presence of pulmonary infection, change the current humidification method halfway. The severity of STBI was classified according to the GCS (15), and patients were divided into two groups according to the severity of their scores: those scoring between $3-5$ points and those scoring between 6-8 points. The patients were supplied with a low rate of supplemental oxygen in the first 7 days of acute injury, and thereafter supplemental oxygen was ceased for patients with spontaneous respiration.

\section{Regular nursing and the respiratory tract humidification method}

All patients were fitted with disposable tracheotomy kits 

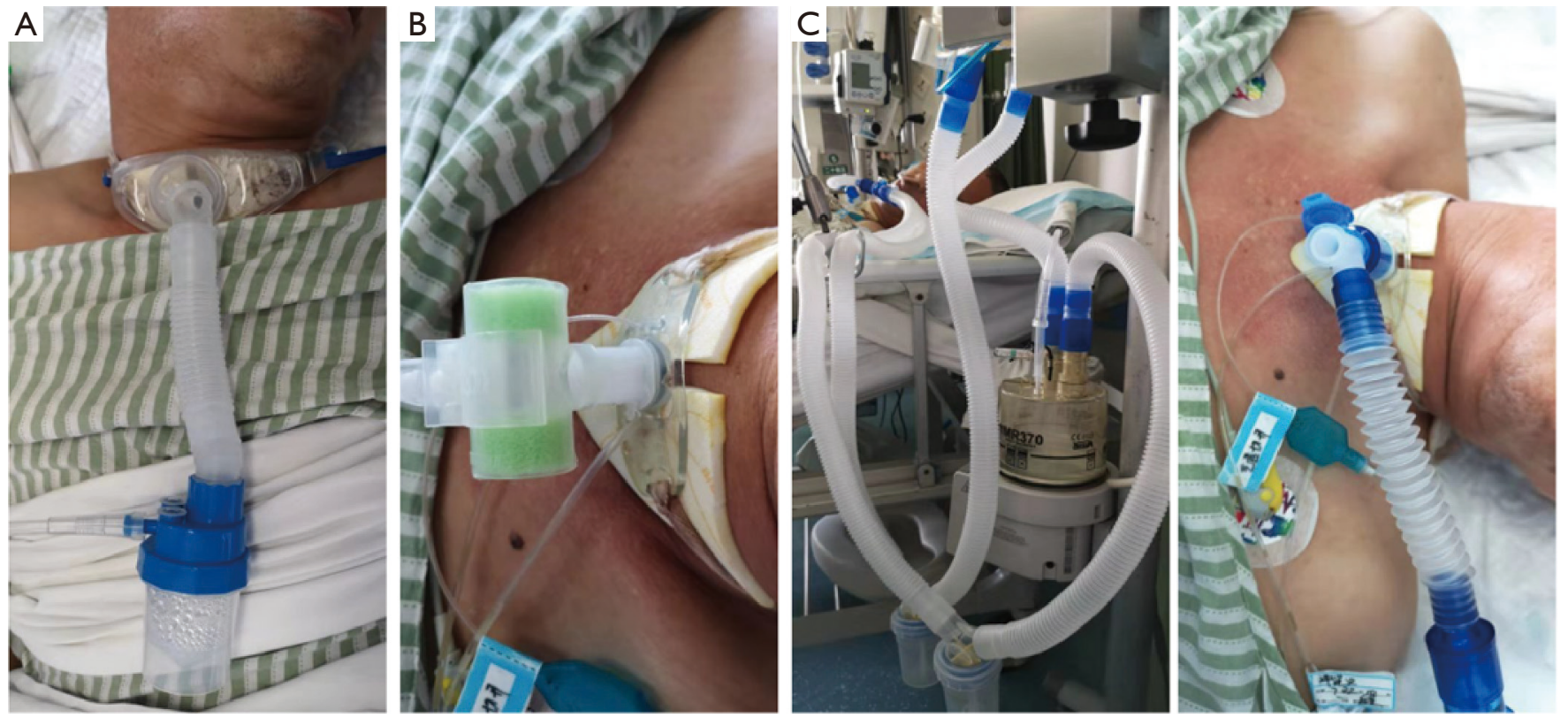

Figure 1 The images showing how the devices were connected in the three methods. The tubes connecting of (A) oxygen atomizer (OA), (B) heat and moisture exchangers (HMEs), and (C) the heated humidifiers (HHs).

produced by Covidien Llc, and a disposable sputum suction tube was used for sputum induction (Figure 1A). Sterilized injection water was chosen as the standard gas-humidifying fluid, and the different humidifying methods that were performed are described below.

OA group: Routine treatment or nursing was performed, in addition to oxygen atomization with $20 \mathrm{~mL}$ humidifying fluid added every 2 hours and replaced every 24 hours. The oxygen atomization devices were purchased from Excellent Care Medical Ltd (Huizhou, China) (product name: Disposable Medical Atomizer EM06-007). An example of the device is shown in Figure $1 \mathrm{~A}$.

HMEs group: Routine treatment or nursing was performed, in addition to the application of the (HMEs), with the artificial nosepiece being replaced every 24 hours or when the sponge was contaminated. The HMEs device was provided by the Inter Surgical Company (Changzhou, China) (product name: Hydro-Trach II HME with oxygen tubing). The tube was directly connected to the end of the tracheal cannula, the middle tube was connected to the oxygen supplying tube, and the sponge on either side was designed to collect the exhaled heat and moisture. An example of the device is shown in Figure $1 B$.

HHs group: Routine treatment or nursing was performing, in addition to heating and humidification treatment, the heated humidifiers were purchased from Hamilton Medical (Switzerland), equipment register number: SFDA(I)20093540261. The device was operated refer to manufacturer's instructions for details of installation. And how the tubes were connected to the patient was indicated in Figure 1C. The temperature of the atomizer tank should be adjusted to $39-41^{\circ} \mathrm{C}$, and the temperature before entering the patient's airway was $35.3^{\circ} \mathrm{C}$ according to a previous report (16). The pipeline is nonpolluting and does not need to be replaced.

All three groups of patients were given routine care including $3 \mathrm{~L} / \mathrm{min}$ oxygen flow, routine hemostasis, blood pressure monitoring, reduction of intracranial pressure, and delivery of enteral nutritional support. And all the patients received routine drug treatment including administrate with the hemostatic, mannitol in the first 3 days, and drugs to nourish brain nerve regularly. The antibiotic was used only after the infection was happened.

\section{Evaluation indicators and standards}

The following indicators were observed on days 1, 3, 5 and 7 after the commencement of the airway humidification method 1 .

(I) Phlegm viscosity (levels I-III). Level I: thin 
phlegm dilution resembling rice soup or white foam that can be easily coughed up. After sputum induction, there is no sputum retention on the tubing. Level II: moderately sticky phlegm that is more difficult to cough up. After sputum induction, there is a small amount of sputum on the tubing. Level III: moderately viscous phlegm of yellow appearance that is difficult to cough up. The phlegm suction tube collapses due to heavy negative pressure, and there is a large amount of sputum on the tubing wall which is not easily cleaned with water.

(II) Formation of phlegm scab. Patient is observed with a phlegm scab produced by the water evaporated from the sputum adhered on the tube conjunction sites.

(III) Airway spasm. Sudden cough, choking, breathing difficulties, or cyanosis is observed.

(IV) Humidification effect. This was classified into the following grades: insufficient humidification $=$ mucous liquid, characterized by a lower viscosity of sputum, lack of absorbability, and thick or dry breathing sounds; good humidification $=$ thin sputum, characterized by a moderate amount of sputum that is easy to absorb, and clear breathing; excessive humidification =foamy, abundant, and inexhaustible sputum, with rapid or rough sounding breathing.

(V) Number of average daily sputum inductions. The daily average sputum induction times= total sputum induction times/total in-hospital days of the patients in each group.

(VI) The degree of secondary lung infection: The secondary lung infection degrees was evaluated according to a previous report (17), the score consists of body temperature, secretion, white cells, X-ray image, airway bacteria culture results and air exchange index, each column was divided into 0,1 and 2 score, and totally 12 scores. Level I was defined as $1-4$ points, level II as $5-8$ points, and level III as $9-12$ points.

(VII) Average nursing time: This was defined as the number of times a nurse attended each patient each day, including daily basic care and intergroup differences in care.

(VIII) Internal satisfaction: This referred to the evaluation of personal job satisfaction by nurses during the study.

\section{Satisfaction survey}

We use the modified version of the Minnesota Satisfaction Questionnaire (MSQ) to measure the workload satisfaction ratings of nursing staff during the study (18). The scale has a total of 20 items. Items $1-4,7-11,15-16$, and 20 in the scale constitute the internal satisfaction and measure the satisfaction of employees with the relevant factors of the job itself. Each issue could be evaluated as "very unsatisfactory", "unsatisfactory", "general", "satisfactory", or "very satisfactory", and ranked on a scale of $1-5$ points, respectively.

\section{Statistical analysis}

SPSS software was used for all statistical analyses. The viscosity of sputum, the humidification effect, and the degrees of secondary lung infection were tested by rank and sum. The patients' disease distribution, phlegm scab formation, and airway spasm were analyzed using Chi square test. The patients' basic condition, daily sputum induction times, respiration-related physiological indicators, daily nursing times, and internal satisfaction scores were analyzed with analysis of variance (ANOVA). P values $<0.05$ were considered statistically significant.

\section{Results}

\section{Basic characters of the patients}

In this study, the effects of three common respiratory tract humidification methods were evaluated. There were 150 patients included in our study aged between 18 and 70 years old. The average age, average in patient duration, sex, and GCS score did not differ between the three groups (Table 1).

\section{Comparison of respiratory related functions and index}

The blood oxygen partial pressure, blood oxygen saturation, and respiratory frequency showed no significant differences between HMEs and HHs. The blood oxygen partial pressure and blood pressure saturation were significantly lower in OA compared with that in HMEs and HHs, and the respiratory frequency in $\mathrm{OA}$ was statistically higher than that in HMEs and $\mathrm{HHs}(\mathrm{P}<0.05)$ (Table 2).

\section{Comparison of humidification effects and the related index}

As Table 3 shows, the degree of sputum viscosity showed 
Table 1 Summary of the main patient characteristics

\begin{tabular}{|c|c|c|c|c|c|c|}
\hline Groups & Average age & $\begin{array}{l}\text { Average in-hospital } \\
\text { time (d) }\end{array}$ & \multicolumn{2}{|c|}{ Gender } & \multicolumn{2}{|c|}{ GCS score } \\
\hline OA & $41.5 \pm 2.5$ & $57.4 \pm 4.8$ & 30 & 20 & 28 & 32 \\
\hline HMEs & $40.8 \pm 3.1$ & $59.2 \pm 5.9$ & 32 & 18 & 31 & 29 \\
\hline $\mathrm{HHs}$ & $41.9 \pm 2.8$ & $58.3 \pm 4.1$ & 29 & 21 & 27 & 33 \\
\hline$P$ & 0.144 & 0.200 & \multicolumn{2}{|c|}{0.822} & \multicolumn{2}{|c|}{0.749} \\
\hline
\end{tabular}

GCS, Glasgow Coma Scale; OA, oxygen atomizer; HMEs, heat and moisture exchangers; HHs, the heated humidifiers.

Table 2 Main respiratory indicators in the three groups

\begin{tabular}{lccc}
\hline Groups & $\mathrm{PO}_{2}(\mathrm{kPa})$ & $\mathrm{SpO}_{2}(\%)$ & $\begin{array}{c}\text { Respiratory rate } \\
\text { (times } / \mathrm{min})\end{array}$ \\
\hline $\mathrm{OA}$ & $10.91 \pm 2.11^{\star^{\#}}$ & $93.75 \pm 2.11^{\star^{*}}$ & $24.12 \pm 2.25^{\star^{*}}$ \\
HMEs & $12.74 \pm 2.59$ & $94.05 \pm 1.65$ & $22.23 \pm 2.15$ \\
$\mathrm{HHs}$ & $13.54 \pm 2.26$ & $96.14 \pm 1.26$ & $20.34 \pm 1.88$ \\
$\mathrm{~F}$ & 16.76 & 29.02 & 12.77 \\
$\mathrm{P}$ & $<0.001$ & $<0.001$ & $<0.001$ \\
\hline
\end{tabular}

*, compared with HMEs; \#, compared with $\mathrm{HHs}$. $\mathrm{PO}_{2}$, partial pressure of oxygen; $\mathrm{SpO}_{2}$, oxygen saturation, $\mathrm{OA}$, oxygen atomizer, $\mathrm{HMEs}$, heat and moisture exchangers, $\mathrm{HHs}$, the heated humidifiers.

an increase trend over the first 7 days, suggesting that further changes might be significant in the following days. With the passing of time after tracheotomy, the viscosity degree of the airway sputum in OA displayed the fastest progression, and patients in OA group showed a greater degree of high-level viscous sputum. Table 4 shows the statistical differences of the humidification effects between the three groups $(\mathrm{P}<0.05)$. OA experienced a greater degree of insufficient or excessive humidification, and patients use HMEs and HHs showed the highest ratio of appropriate humidification. OA had the fewest sputum induction times, while HMEs and HHs had similar times, indicating equal humidification effects. In OA group, scab formation was significantly greater than that of HMEs and HHs $(\mathrm{P}<0.05)$. The incidence of airway spasm was significantly greater in OA compared to HMEs or HHs $(\mathrm{P}<0.05)$.

\section{Comparison of the secondary respiratory infection ratio}

After comparing the degree of secondary infection in the first 7 days (Table 5), we observed that secondary pneumonia occurred in all three groups, but HHs showed the lowest infection ratio $(\mathrm{P}<0.05)$. However, the severity of infection did not differ between the three groups. On day 30, the secondary pneumonia infection ratio showed no difference among the three groups, but the severity of infection differed significantly. The number of patients with level III infections was significantly lower in HHs compared to the other two groups $(\mathrm{P}<0.05)$, but there was no difference between OA and HMEs.

\section{Comparison of the workload and job satisfaction}

The results of the job satisfaction survey (Table 6) rated by nursing staff showed that OA had the lowest average daily nursing times and nursing load compared with HMEs and $\mathrm{HHs}$, but there was no difference between HMEs and HHs. Nursing staff also rated work intensity as significantly greater in HMEs and HHs than in $\mathrm{OA}(\mathrm{P}<0.05)$. There were no statistically significant differences between groups on any other items.

\section{Discussion}

Patients with severe traumatic brain injury often experience concomitant respiratory disorders, and a tracheotomy is often required in order to prevent deterioration in their condition. After the tracheotomy is performed, airway humidification is required to prevent injury to the airway mucosa or any further neuronal damage (19). Patients with severe traumatic brain injury are often hospitalized for an extended period of time; therefore, choosing an appropriate airway humidification method is important in reducing complications and patient discomfort. In this study, we selected three relatively common humidification methods 
Table 3 Comparisons of the sputum viscosity in the three groups on different days

\begin{tabular}{|c|c|c|c|c|c|c|c|c|c|c|c|c|}
\hline Groups & \multicolumn{3}{|c|}{ 1st day } & \multicolumn{3}{|c|}{ 3rd day } & \multicolumn{3}{|c|}{ 5th day } & \multicolumn{3}{|c|}{ 7th day } \\
\hline OA & 48 & 1 & 1 & 42 & 4 & 4 & 37 & 6 & 7 & 32 & 8 & 10 \\
\hline HMEs & 46 & 2 & 2 & 43 & 5 & 2 & 42 & 4 & 4 & 41 & 5 & 4 \\
\hline $\mathrm{HHs}$ & 47 & 2 & 1 & 47 & 2 & 1 & 46 & 3 & 1 & 44 & 3 & 3 \\
\hline$P$ & \multicolumn{3}{|c|}{0.918} & \multicolumn{3}{|c|}{0.464} & \multicolumn{3}{|c|}{0.161} & \multicolumn{3}{|c|}{0.051} \\
\hline
\end{tabular}

$\mathrm{OA}$, oxygen atomizer; HMEs, heat and moisture exchangers; HHs, the heated humidifiers.

Table 4 Comparison of airway humidification effects, sputum induction times, formation of phlegm scab, and airway spasm among the three groups

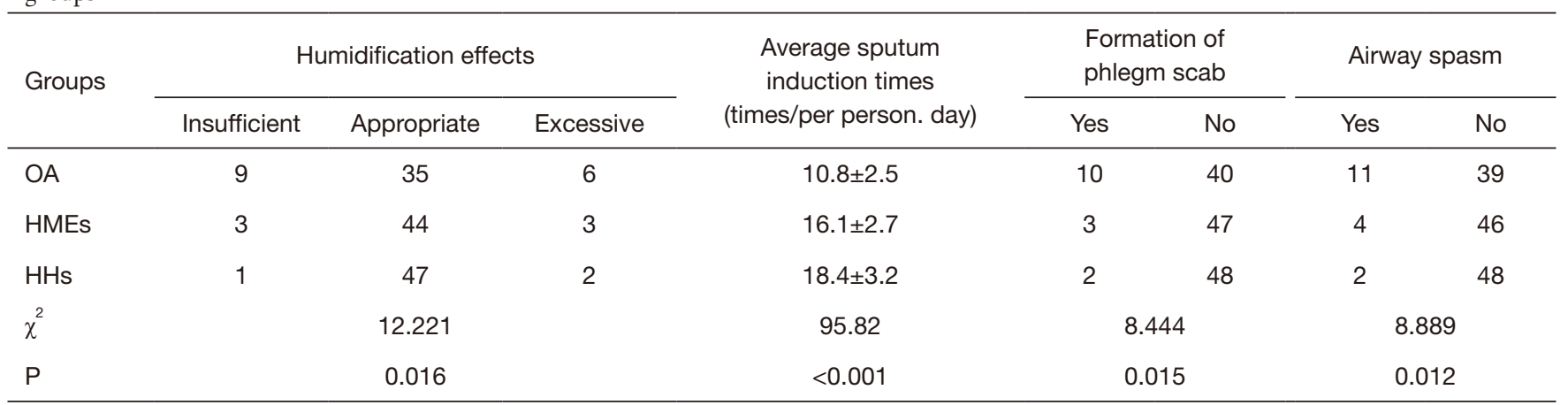

OA, oxygen atomizer; HMEs, heat and moisture exchangers; HHs, the heated humidifiers.

Table 5 Comparison of secondary infection occurrence on the 7th and 30th days among the three groups

\begin{tabular}{|c|c|c|c|c|c|c|c|c|}
\hline Groups & $\begin{array}{l}\text { Infection rate } \\
\text { (7th day) }\end{array}$ & \multicolumn{3}{|c|}{ Infection degree (7th day) } & $\begin{array}{l}\text { Infection rate } \\
\text { (30th day) }\end{array}$ & \multicolumn{3}{|c|}{ Infection degree (30th day) } \\
\hline OA & $32 \%$ & 12 & 2 & 2 & $90 \%$ & 14 & 15 & 13 \\
\hline HMEs & $24 \%$ & 8 & 3 & 1 & $94 \%$ & 16 & 19 & 6 \\
\hline $\mathrm{HHs}$ & $16 \%$ & 9 & 2 & 1 & $86 \%$ & 23 & 14 & 3 \\
\hline$P$ & 0.173 & & 0.929 & & 0.441 & & 0.032 & \\
\hline
\end{tabular}

OA, oxygen atomizer, HMEs, heat and moisture exchangers, $\mathrm{HHs}$, the heated humidifiers.

and compared their effects on airway humidification in patients with severe traumatic brain injury. Through evaluation of the relevant indicators, we found that all three methods can effectively maintain the patient's respiratoryrelated indicators within the normal range, but the $\mathrm{HHs}$ method has comparative advantages.

In this study, we chose to evaluate the three methods in the first 7 days following tracheotomy as clinical data for this period were relatively intact, and after this time patients were often discharged to other specialist hospitals or hospitals nearer to their home for further therapy. In this study, we chose to deliver a low rate of oxygen during the initial acute injury stage to ensure an adequate oxygen supply to the brain, and to establish a higher $\mathrm{SpO}_{2}$ and lower respiratory rate in patients who were spontaneously breathing. Given that $67 \%$ of patients with severe brain 


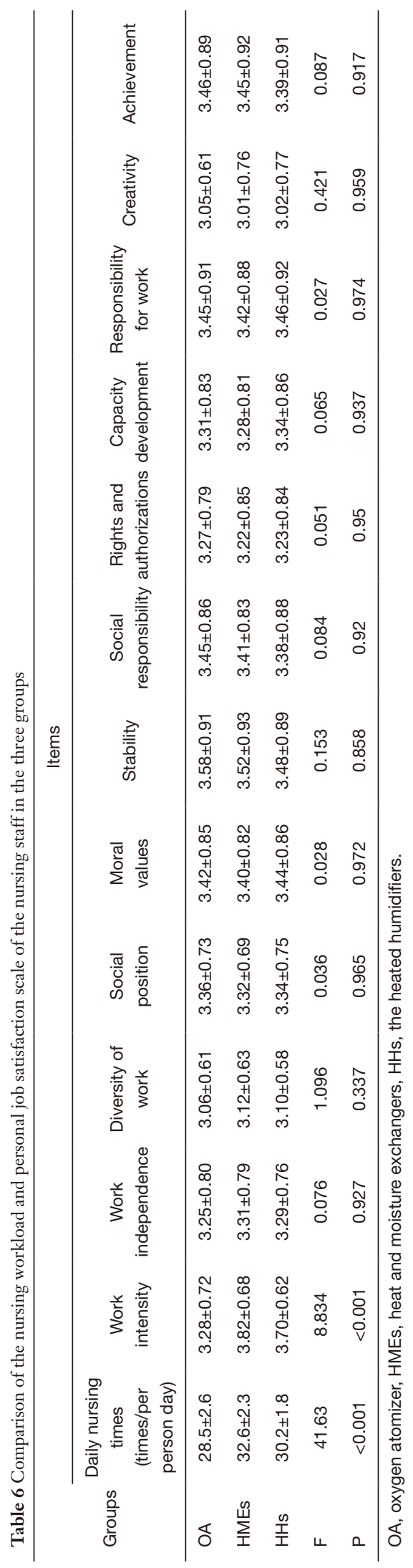

injury suffer cerebral hypoxia in the acute stage, but that over-oxygenation can induce injury to the lung tissues, we chose 7 days as an appropriate timeframe in our study. Previous studies $(16,20)$ have indicated that the HHs usually gains a better $\mathrm{SpO}_{2}$, but our results showed that the $\mathrm{SpO}_{2}$ was lower and the respiratory rate was higher in HMEs and $\mathrm{HH}$ s than OA, and no difference was observed between HMEs and HHs. It could be that the colder temperature of the air flow in OA caused the airway to contract, thus preventing oxygen exchange, and that the supplemental oxygen delivered to the patients diminished the differences between HMEs and HHs.

It is common knowledge that blood oxygen concentrations decrease when cold air or coughing causes the airway to spasm (21), and that the temperature of inspired gas is closely related to airway function (22). In the HMEs and HHs groups, the air flow is heated and humidified, which is more comfortable and less likely to cause an airway reaction. When the airway is surgically cut, the warming and humidifying process of the upper respiratory tract on the gas disappears. Therefore, as the airway opens up, the viscosity of the phlegm in each group increases, although this process was slowed in the HMEs and $\mathrm{HH}$ sroups. Compared to HMEs and $\mathrm{HH}$, the $\mathrm{OA}$ usually results in inferior and insufficient humidification effects. In addition, patients with severe traumatic brain injury often require a significant amount of dehydrating agents, thereby aggravating the dryness of the airway, which is then more likely to cause a viscous scab in the airway which increases the chance of a lung infection (23). For these reasons, the patients in OA group needed the least sputum induction procedures, but were more likely to form a phlegm scab.

Currently, HMEs is a commonly used airway humidification method in major hospitals, largely due to its highly effective humidification effect (24). However, Boots et al. reported that HMEs increases airway resistance after 24 hours of continuous usage, so they need to be replaced every day (25). The OA used is relatively cost-effective and humidifying, but it is not stable and requires a subjective evaluation from the nurse which may cause excessive or insufficient humidification. It may also generate a large amount of foam secretions that cause coughing or shortness of breath, thus reducing oxygen saturation. Furthermore, it is labor intensive for nursing staff who are required to continuously monitor the amount of humidification being delivered.

The HMEs is designed to use the moisture from the 
patient's exhaled breath to achieve a better humidification effect, so it is as effective in reducing airway stimulation and good humidification as the HHs, but the excreted sputum will be directly absorbed on the filtration network. If the sponge is contaminated by sputum, nursing staff are required to clean the sputum-absorbing sponge frequently (approximately every 2 hours), which greatly increases their workload. Furthermore, changing the contaminated sponge frequently causes the release of heat and moisture, and makes it more likely that patients will experience insufficient humidification and an increase in the viscosity of sputum. Although HMEs requires less suctioning time than HHs, nursing staff spend more time cleaning the sponges in HMEs, and hence the nursing load is not significantly reduced.

The use of a humidifier can significantly increase the relative humidity and temperature of the air flow (26), and as shown in this study, HHs can provide the best humidity and temperature. This in turn can reduce airway spasm, which is conducive to the formation and discharge of sputum. The excretion of sputum is beneficial in reducing the incidence of secondary pneumonia. Although the outlet tubes of the device in HHs restrict the patient's movement, it is a suitable method for patients with severe traumatic brain injury who are bedridden for an extended period of time. In this study, the data were collected from our trauma center, and we focused on the humidification effects on STBI patients, but our conclusions may also apply to other patients needing a high quality of airway humidification. The limitation of this study was that our evaluation of the humidification effects of these three methods focused only on the first 7 days following tracheotomy, and further studies will be required to evaluate the long-term effects of these three methods.

In conclusion, we compared the humidification effects of three common airway humidification methods used for severe traumatic brain injury patients and found that the $\mathrm{HHs}$ is more suitable for patients who are bedridden for extended periods of time.

\section{Acknowledgments}

Funding: This study was supported by the Science and Technology Fund of Changzhou (WZ201528).

\section{Footnote}

Reporting Checklist: The authors have completed the
STROBE reporting checklist. Available at http://dx.doi. org/10.21037/apm-20-2135

Data Sharing Statement: Available at http://dx.doi. org/10.21037/apm-20-2135

Conflicts of Interest: All authors have completed the ICMJE uniform disclosure form (available at http://dx.doi. org/10.21037/apm-20-2135). The authors have no conflicts of interest to declare.

Ethical Statement: The authors are accountable for all aspects of the work in ensuring that questions related to the accuracy or integrity of any part of the work are appropriately investigated and resolved. The study was approved by the Ethics Committee of the Changzhou Tumor Hospital (2019-SY-014), and all patients gave consent to participate in the study. All procedures performed in this study involving human participants were in accordance with the Declaration of Helsinki (as revised in 2013).

Open Access Statement: This is an Open Access article distributed in accordance with the Creative Commons Attribution-NonCommercial-NoDerivs 4.0 International License (CC BY-NC-ND 4.0), which permits the noncommercial replication and distribution of the article with the strict proviso that no changes or edits are made and the original work is properly cited (including links to both the formal publication through the relevant DOI and the license). See: https://creativecommons.org/licenses/by-nc-nd/4.0/.

\section{References}

1. Lu Q, Xie Y, Qi X, et al. Is Early Tracheostomy Better for Severe Traumatic Brain Injury? A Meta-Analysis. World Neurosurg 2018;112:e324-30.

2. Lucato JJ, Tucci MR, Schettino GP, et al. Evaluation of resistance in 8 different heat-and-moisture exchangers: effects of saturation and flow rate/profile. Respir Care 2005;50:636-43.

3. Pakkanen T, Nurmi J, Huhtala H, et al. Prehospital onscene anaesthetist treating severe traumatic brain injury patients is associated with lower mortality and better neurological outcome. Scand J Trauma Resusc Emerg Med 2019;27:9.

4. Eshel I, Bowles AO, Ray MR. Rehabilitation of Cognitive Dysfunction Following Traumatic Brain Injury. Phys Med 
Rehabil Clin N Am 2019;30:189-206.

5. Tudor RM, Thompson CJ. Posterior pituitary dysfunction following traumatic brain injury: review. Pituitary 2019;22:296-304.

6. McNamara DG, Asher MI, Rubin BK, et al. Heated humidification improves clinical outcomes, compared to a heat and moisture exchanger in children with tracheostomies. Respir Care 2014;59:46-53.

7. American Association for Respiratory Care, Restrepo RD, Walsh BK. Humidification during invasive and noninvasive mechanical ventilation: 2012. Respir Care 2012;57:782-8.

8. Pan Y. Effect of Oxygen Atomized Inhalation and Ultrasonic Atomized Inhalation on Airway Humidification in Patients with Severe ICU in Neurosurgery. China Medical Device Information 2020;26:137-9.

9. Zhu D, Wu M, Cao Y, et al. Heated humidification did not improve compliance of positive airway pressure and subjective daytime sleepiness in obstructive sleep apnea syndrome: A meta-analysis. PLoS One 2018;13:e207994.

10. Nilius G, Domanski U, Schroeder M, et al. Mask humidity during CPAP: influence of ambient temperature, heated humidification and heated tubing. Nat Sci Sleep 2018;10:135-42.

11. Chikata Y, Oto J, Onodera M, et al. Humidification performance of humidifying devices for tracheostomized patients with spontaneous breathing: a bench study. Respir Care 2013;58:1442-8.

12. Liu L, Liang Y, Wang X, et al. Comparison of application of two atomization inhalation methods in post-thoracoscopy operative patients with lung cancer. China Modern Doctor 2016;54, 40-42, 45.

13. Gillies D, Todd DA, Foster JP, et al. Heat and moisture exchangers versus heated humidifiers for mechanically ventilated adults and children. Cochrane Database Syst Rev 2017;9:CD004711.

14. Ding L. The Application Effect of Artificial Airway Humidification Method in Severe Traumatic Brain Injury Patients. China Continuing Medical Education 2017;9:166-67.

15. Emami P, Czorlich P, Fritzsche FS, et al. Impact of Glasgow Coma Scale score and pupil parameters on mortality rate and outcome in pediatric and adult severe traumatic brain injury: a retrospective, multicenter cohort study. J Neurosurg 2017;126:760-7.

16. Nakanishi N, Oto J, Itagaki T, et al. Humidification Performance of Passive and Active Humidification Devices Within a Spontaneously Breathing Tracheostomized Cohort. Respir Care 2019;64:130-5.
17. Luna CM, Blanzaco D, Niederman MS, et al. Resolution of ventilator-associated pneumonia: prospective evaluation of the clinical pulmonary infection score as an early clinical predictor of outcome. Crit Care Med 2003;31:676-82.

18. Olsen TW, Liao A, Robinson HS, et al. The Nine-Step Minnesota Grading System for Eyebank Eyes With Age Related Macular Degeneration: A Systematic Approach to Study Disease Stages. Invest Ophthalmol Vis Sci 2017;58:5497-506.

19. Oberholzer M, Müri RM. Neurorehabilitation of Traumatic Brain Injury (TBI): A Clinical Review. Med Sci (Basel) 2019;7:47.

20. Corley A, Edwards M, Spooner AJ, et al. High-flow oxygen via tracheostomy improves oxygenation in patients weaning from mechanical ventilation: a randomised crossover study. Intensive Care Med 2017;43:465-7.

21. Kaminsky DA, Lynn M. Pulmonary capillary blood volume in hyperpnea-induced bronchospasm. Am J Respir Crit Care Med 2000;162:1668-73.

22. Williams R, Rankin N, Smith T, et al. Relationship between the humidity and temperature of inspired gas and the function of the airway mucosa. Crit Care Med 1996;24:1920-9.

23. Gaab M, Knoblich OE, Schupp J, et al. Effect of furosemide (lasix) on acute severe experimental cerebral edema. J Neurol 1979;220:185-97.

24. Boyer A, Thiéry G, Lasry S, et al. Long-term mechanical ventilation with hygroscopic heat and moisture exchangers used for 48 hours: a prospective clinical, hygrometric, and bacteriologic study. Crit Care Med 2003;31:823-9.

25. Boots RJ, George N, Faoagali JL, et al. Double-heaterwire circuits and heat-and-moisture exchangers and the risk of ventilator-associated pneumonia. Crit Care Med 2006;34:687-93.

26. Martins De Araújo MT, Vieira SB, Vasquez EC, et al. Heated humidification or face mask to prevent upper airway dryness during continuous positive airway pressure therapy. Chest 2000;117:142-7.

(English Language Editors: D. Fitzgerald and J. Reynolds)

Cite this article as: Yin X, Yang L, Sun H, Yun Z, Wang Y, Ma B. A comparative evaluation of three common airway humidification methods for patients with severe traumatic brain injury. Ann Palliat Med 2020;9(6):4137-4145. doi: 10.21037/ apm-20-2135 